\title{
Reflektans konfokal mikroskopi; normal deri morfolojisi ve melanositik lezyonlarda kullanımı
}

\author{
Reflectance confocal microscopy: its use in melanocytic \\ lesions and morphology of normal skin
}

Aslı Vefa Turgut Erdemir, Ayșe Esra Koku Aksu

İstanbul Eğitim ve Araștırma Hastanesi, Dermatoloji Kliniği, İstanbul, Türkiye

Özet

İn vivo Reflektans Konfokal Mikroskopi (RKM); canlı deride, hücre ve diğer yapıların histolojik analize yakın düzeyde görüntülenmesini sağlayan noninvaziv bir tanı yöntemidir. Epidermis, papiller dermis ve yüzeyel retiküler dermisdeki dinamik olayların değerlendirilmesine olanak sağlar. Stratum korneumdan başlayarak maksimum 350 mm derinliğe kadar incelenebilir. Bu yöntemin noninvaziv özelliği, etkilenen alanda hasara yol açmadan tekrarlayan görüntüleme yapma ve tedavi yanıtının değerlendirilmesine olanak sağlar. RKM, melanin ve melanozomların yüksek kontrast kaynağı olması nedeni ile normal derinin ve özellikle melanositik deri lezyonlarının değerlendirilmesinde büyük kolaylıklar sağlamaktadır. Bu makalede RKM ile normal deri morfolojisi ve melanositik lezyonlarının özellikleri anlatımaktadır. (Türkderm 2013; 47: 136-41)

Anahtar Kelimeler: Melanositik deri lezyonları, reflektans konfokal mikroskopi

\section{Summary}

In vivo reflectance confocal microscopy (RCM) is a noninvasive diagnostic method that allows imaging of cells and structures in living skin at high resolution with precision almost similar to histological analysis. RCM allows the assessment of dynamic events in the epidermis, papillary dermis and the superficial reticular dermis. From the stratum corneum to a depth of a maximum of 350 $\mathrm{mm}$ can be analysed. The noninvasive feature of this technique allows repetitive imaging without any damage to the affected area and to evaluate the response to the treatment. RCM provides great convenience in the assessment of normal skin and particularly in evaluating melanocytic lesions due to high contrast features of melanins and melanosomes. In this article, morphology of normal skin and features of melanocytic lesions are described with RCM. (Turkderm 2013; 47: 136-41)

Key Words: Melanocytic skin lesions, reflectance confocal microscopy

\section{Giriş}

RKM yönteminin temel prensipleri ilk olarak Marvin Minsky tarafından 1957 yılında tanımlanmıştır, ancak teknolojinin insan derisinin görüntülenmesi için geliştirilmesi birkaç dekat sürmüştür. RKM'in insan derisinin görüntülenmesinde kullanılması ve tanımlama ilk olarak Rajadhyaksha ve arkadaşları tarafından 1995 yılında gerçekleşmiştir ${ }^{1}$. Melanin ve melanozomlar, kuvvetli kontrast kaynağı olması nedeni ile görüntülerde parlak yapılar şeklinde karşımıza çıkmaktadır ${ }^{1}$. Bu durum konfokal araştırmalarının melanositik lezyonlar üzerinde yoğunlaşmasına neden olmuştur. Nevüslerin ve melanomun morfolojik özellikleri ilk olarak 2001 yılında tanımlanmıştır2,3. Yakın zamanda melanom tanısında farklı tanısal algoritmalar geliştirilmiştir4-7 Konfokal mikroskopinin kullanıldığı diğer araştırma alanları non melanositik lezyonlar ve enflamatuvar deri lezyonlarıdır.

Yazışma Adresi/Address for Correspondence: Dr. Assı Vefa Turgut Erdemir, İstanbul Eğitim ve Araştırma Hastanesi, Dermatoloji Kliniği, İstanbul, Türkiye GSM: +90 5052685651 E-posta: vefaasli@hotmail.com Geliş Tarihi/Received: 14.08.2013 Kabul Tarihi/Accepted: 28.08.2013 


\section{Reflektans Konfokal Mikroskopi Çalışma İlkesi ve Özellikleri}

RKM'de deriye penetre olan ve doku içindeki küçük bir noktayı aydınlatan monokromatik ışık kaynağı olarak diode lazer kullanılmıştır. Aydınlanan bu alandan yansıyan ışık, küçük iğne deliği açıklığı (pinhole) şeklindeki bölgeye gider ve dedektörde bir görüntü oluşturur. Iğne deliği açıklığı diğer doku bölümlerinden yansıyan ışığın detektöre ulaşmasına engel olur. Bu nedenle sadece fokal bir alandan yansıyan ışığın tespit edilmesi konfokal teriminin ortaya çıkmasına neden olmuştur (Resim 1). Dijital görüntülemede, temel eleman pixel olarak adlandırılan ufak noktacıkların yatay ve dikey biçimde yanyana sıralanması ile görüntüler oluşması esasına dayanır.

RKM ile elde edilen çözünürlük iğne deliği açıklığın boyutuna, objektif lenslerin sayısal açıklığına ve kullanılan dalga boyuna bağlıdır. Günümüzde RKM için farklı dalga boylarındaki lazerler ışık kaynağı olarak kullanılmaktadır. Uzun dalga boyları daha derine penetre olurken lateral çözünürlükleri daha zayıftır. Kızıl ötesine yakın dalga boyları (800-1064 nm), melanozomlardan güçlü bir geri saçılma oluşturur. Bazal keratinositler ve melanositler gibi melanin içeren hücreler parlak bir görüntü verir. Yine eğer deri rengi koyu ise veya lezyon pigmente ise daha fazla kontrast izlenebilir8.

Günümüzde kullanılan konfokal mikroskopi $830 \mathrm{~nm}$ diode lazer veya çoklu dalga boylarına sahip (488 nm, 658 nm ve 785 nm) floresan filtreli mikroskoptur. Lazer ışını hava boşluğunu geçerken ışın sapmasını en aza indirgemek için epidermisin refraktil indeksine yakın su bazlı jeller kullanılır. Görüntülerde lateral çözünürlük 0,5-1,0 mikron $(\mu)$ ve kesit kalınlığı 2-5 $\mu \mathrm{m}$ arasında değişmektedir. X30 ojektif lens ve 0,9 sayısal açıkık(NA) genellikle 0,5 mm'lik bir alanın optik kesit kalınlığı $3 \mu \mathrm{m}$ ve lateral çözünürlük $0,7 \mu \mathrm{m}$ olacak şekilde görüntülenmesini sağlar. Böylece 250-300 um derinliğe kadar inilerek epidermis, papiller dermis ve retiküler dermisin görüntülenmesi yapılabilir9 .

Görüntülenmek istenen bölge horizontal olarak taranır, 500×500 $\mu$ çapındaki kare mozaiklerden oluşan küçük kadranlar yolu ile RKM mozaikler oluşturulabilir. Odak düzlemin doku içine veya dışına hareket ettirilmesi ile görüntü yığınları(stack) oluşturulabilir. Dinamik olayları görüntülemek amacı ile kısa süreli video kayıtları yapılabilir. Görüntüleme süresi bir lezyon için yaklaşık 5-15 dakika arasındadır ${ }^{10}$. Konfokal mikroskop ve kullanımı ile ilgili görüntüler Resim 2'de gösterilmektedir.

\section{Normal Derinin Konfokal Mikroskopik Özellikleri}

Hücrelerin morfolojik görünümleri, incelenen bölgenin stratum korneumdan olan derinliği ve dermal papillalar gibi farklı yapıların ayırt ettirici özellikleri epidermis tabakalarının birbirinden ayırt edilmesinde önemli özelliklerdir (Tablo 1). Elde edilen görüntüler histolojik kesitlerle oldukça iyi bir uyum gösterir, ancak iki metodu tamamen aynı düzlemde görüntülemek mümkün değildir ${ }^{11}$

Stratum korneum: Hava-deri geçişindeki ilk tabaka stratum korneumdur. Konfokal görüntülerde koyu kontürlerle sınırlandırılmış adalar oluşturan oldukça parlak, büyük (15-30 m), çekirdeksiz poligonal hücreler şeklinde karşımıza çıkar (Resim 3a) ${ }^{12}$.

Stratum granülozum: Epidermisin çekirdekli son tabakasıdır ve stratum korneumdan 15-20 $\mu m$ aşağıda yerleşmiştir. Granüler hücreler 20-35 $\mu \mathrm{m}$ boyutlarında birbirine bitişik bir düzende izlenir. Nükleusu parlak beyaz tanecikli bir sitoplazma halkası ile çevrelenmiş merkezi koyu yuvarlak veya oval yapılar şeklinde görülür. Bu görünüm içerdiği organeller, keratohyalin granülleri ve melanozomlardan kaynaklanmaktadır (Resim 3b)2.

Stratum spinozum: Deri yüzeyinden 20-100 $\mu$ m aşağıda yerleşmiştir. Çapları 15-25 $\mu \mathrm{m}$ arasında olan, küçük, küboidal hücrelerden oluşur. Bu hücrelerin parlak hücre sınırları melanin granülleri ve intersellüler bağlantılardan kaynaklanmaktadır (Resim 3c).

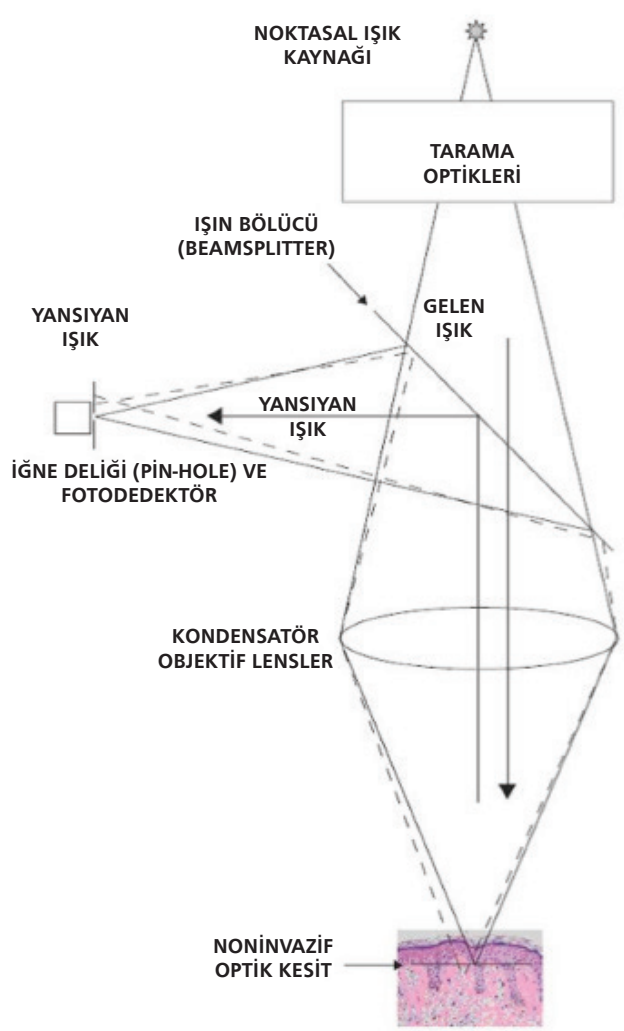

Resim 1. RKM'nin çalışma mekanizması

Tablo 1. Epidermal tabakaların RKM özellikleri11

\begin{tabular}{|l|c|c|l|}
\hline Epidermal tabaka & $\begin{array}{l}\text { Stratum korneumdan } \\
\text { olan uzaklık }(\boldsymbol{\mu m})\end{array}$ & Keratinosit çapı $(\boldsymbol{\mu m})$ & Görünüm \\
\hline Stratum korneum & - & $15-30$ & $\begin{array}{l}\text { Kıvrımlarla birbirinden ayrılmış adalar oluşturan çekirdeksiz poligonal } \\
\text { hücreler } \\
\text { Parlak beyaz halka ile çevrelenmiş büyük oval veya yuvarlak nükleuslu, } \\
\text { tanecikli stoplazmalı bal peteği manzarası gösteren hücreler } \\
\text { Stratum granülozum }\end{array}$ \\
Stratum spinozum & $15-20$ & $20-35$ & $\begin{array}{l}\text { Strum granülozuma benzer şekilde ancak daha az refraktil stoplazmalı } \\
\text { küçük hücreler } \\
\text { Boyutları derin tabakalara indikçe artan oldukça refraktil bazal hücrelerden } \\
\text { oluşan halkalar }\end{array}$ \\
\hline Stratum bazale & $50-100$ & $7-12$ & \\
\hline
\end{tabular}


Stratum spinozum ve stratum granülozum hücreleri parlak granüler stoplazma ve koyu oval-yuvarlak çekirdekleri ile birbirine yapışık bal peteği manzarasını oluşturur'12.

Stratum bazale: Yaklaşık olarak deri yüzeyinden 50-100 um aşağıda tespit edilebilir. Bazal hücrelerin çapları yaklaşık 7-12 $\mu m^{\prime}$ dir. Bu hücreler soliter, parlak, yuvarlak-oval şekilli yapılar şeklinde görüntülenir (Resim 3d). Hücre çekirdekleri koyu halolar şeklindedir. Bazal hücreler kaldırım taşı paterni (cobblestone pattern) oluşturur. Pigmente keratinositler ve melanositler içerdikleri melaninin yüksek refraktilitesi nedeni ile RKM'de oldukça parlak olarak görülürler ${ }^{12}$. Normal deride melanosit ve pigmente bazal keratinosit ayrımını tam olarak yapmak zordur çünkü melanositlerin nadiren denritik uzantıları vardır ve yuvarlak oval yapılar şeklindedirler ${ }^{13}$. Bazal hücreler dermal papillanın etrafında parlak halkalar oluşturur, bu epidermis içinde karanlık delikler şeklinde karşımıza çıkar(kenarlı papilla) ${ }^{12}$.

Dermis: Papiller dermis deri yüzeyinin 50-150 $\mu \mathrm{m}$ altında bulunur9 Dermal papilla koyu, yuvarlak-oval merkezinde vasküler yapıların bulunduğu, parlak bazal hücrelerden oluşmuş halka ile çevrelenmiş homojen alanlar şeklinde karşımıza çıkar (Resim 3e).

Gerçek zamanlı RKM incelemede papiller damarların içerisinde kan akımı gözlemlenebilir. Papiller damarlar çevredeki stromadan daha koyu şekilde görülür. Bu alanlar kollajen liflerle çevrelenmiştir. Bunların arasında yüksek refraktiliteleri nedeni ile melanofajlar kolaylıkla tespit edilir. Melanofajlar üst dermiste kan damarları çevresinde görülürler. Düzensiz şekilli, büyük, oldukça parlak nükleusu olmayan hücrelerdir2. Retiküler dermisin sadece üst bölümü, ince deri alanlarında görülebilir, periferde parlak merkezde koyu kollajen lifleri(5-25 $\mu \mathrm{m})$ tespit edilebilir (Resim 3f).

Kıl folikülleri ve ekrin glandlar gibi deri ekleri de RKM ile görüntülenebilir. Kıl folikülleri pilosebase ünitesi ile birlikte parlak, sirküler, çevresinde uzamış eliptik hücrelerin bulunduğu refraktil uzun kıl folikülleri şeklinde karşımıza çıkar (Resim 4a). Ekrin ter bezleri ortaları koyu, parlak, ovalyuvarlak, spiral yapılar şeklinde epidermis ve dermiste görülür (Resim $4 b)^{10}$.

\section{Melanositik Deri Lezyonları}

Melanositik deri tümörlerinin morfolojik RKM özellikleri ilk olarak Busam ve arkadaşları ve Langley ve arkadaşları tarafından tanımlanmışıı2,3. Sıradan benign nevuslerde bulunan monomorfik özelliklerin yerini atipik nevus ve melanomlarda pleomorfizm ve yapısal düzensizlik almaktadır. Melanositik lezyonların RKM özellikleri dermoskopi ve histopatoloji ile iyi korelasyon göstermektedir12,14-16. RKM, benign ve malign melanositik lezyonların ayııımında faydalıdır 17,18. Melanomun erken evresinde, küçük çaplı melanomlarda ve açık renkli melanostik lezyonların değerlendirilmesinde doğru tanı için dermoskopi ile birlikte RKM incelemesi önem taşımaktadır19-21. RKM ile nevositler genellikle yuvarlak-oval, merkezinde yuvarlak nükleus bulunan refraktil sitoplazmalı hücreler şeklinde görülür2.

Konjenital melanositik nevüs(KMN): Bu nevuslar genellikle bileşik veya intradermaldir. Edinsel banal nevuslerden ayırt edilemezler. Tanı için dermal yapının görülmesi gerektiğinden RKM ile yapılan yüzeyel görüntü yeterli olmamaktadır. KMN basitçe RKM ile benign nevus özellikleri gösterir.

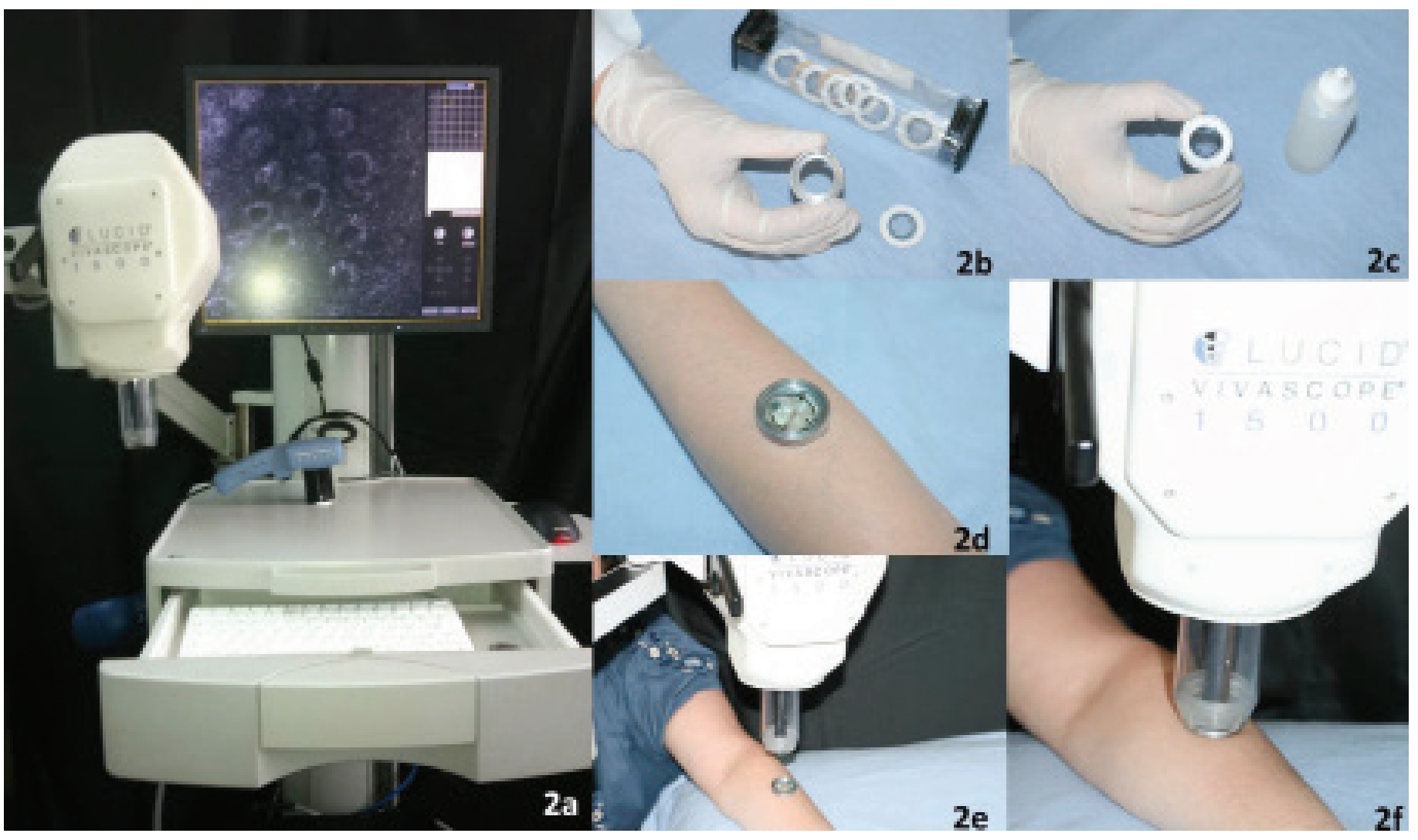

Resim 2. Reflektans Konfokal Mikroskopi ile görüntüleme. 2a; Vivascope 1500. 2b,c; Metal halkaya yapıştırılan pencerenin diğer yüzüne yağ bazlı immersiyon damlatılması 2c; Yağ damlatılan yüzdeki yapıştıııc bant çıkarılarak deri üzerine yerleştirilmesi ve halkanın içerisine su bazlı bir immersiyon jeli koyulması. 2d,e; Vivascope başlığı ve metal halka dik olacak şekilde birleştirilmesi 

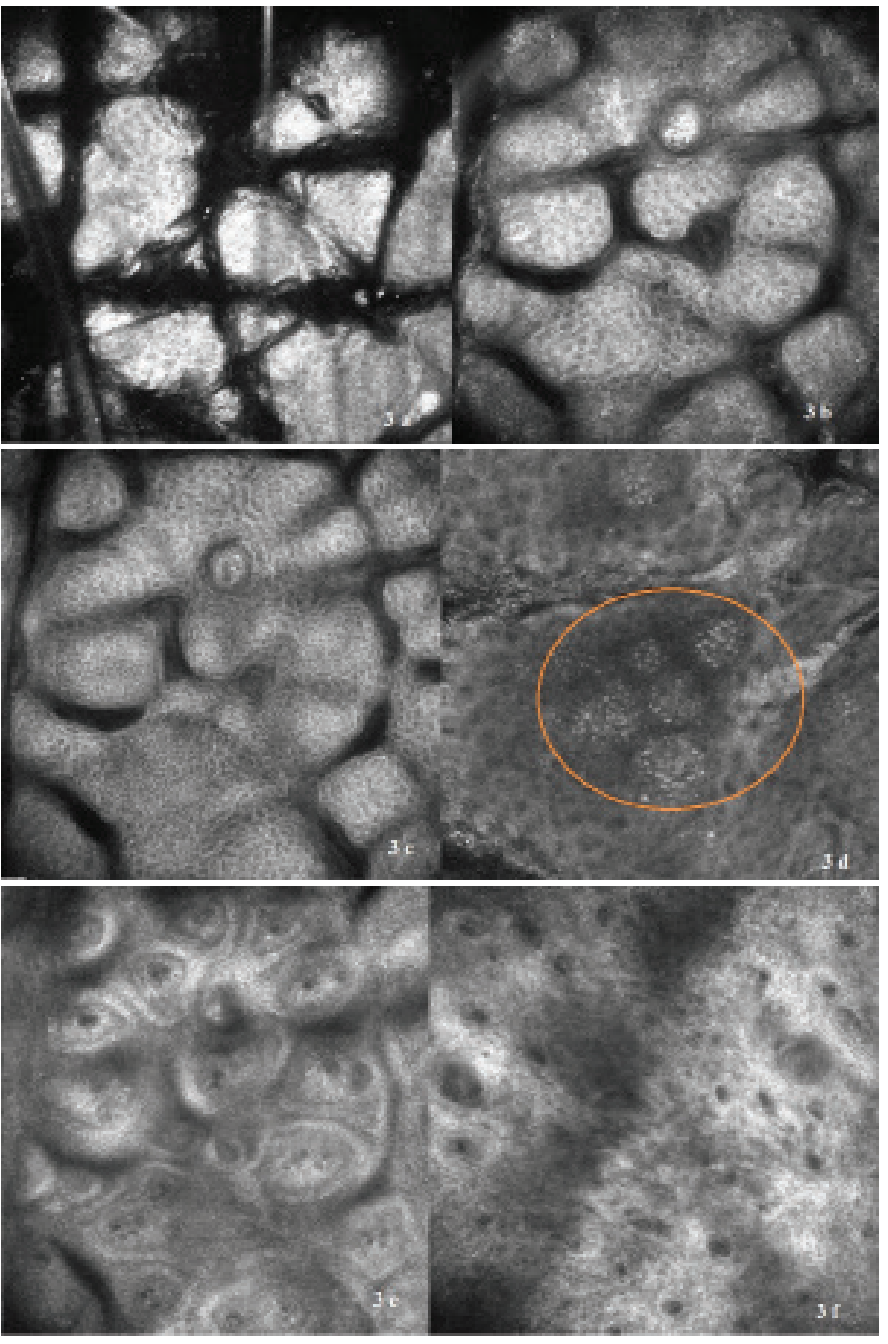

Resim 3. Normal deri. 3a; Stratum korneumda oldukça parlak yüzey ve belirgin deri kıvrımları. 3b; Stratum granülozumda poligonal keratinositler, lezyonun orta kısmında daha derinde stratum spinozum izlenmekte. 3c; Bal peteği manzarası gösteren stratum spinozum. 3d; Stratum bazalenin yüzeyel kısmında biraraya gelerek kümeler oluşturmuş yuvarlak hücrelerden oluşan melanin başlıklar (melanin capturuncu halka). 3e; Dermoepidermal bileşkenin yüzeyel kısımlarında dermal papillayı çevreleyen dermal papiller halkalar 3f; Retiküler yapı gösteren dermal papiller fibriller kollajen)

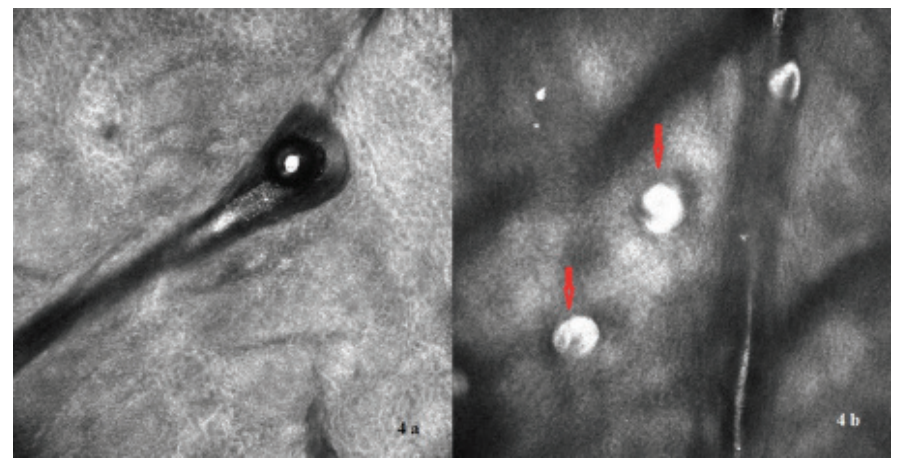

Resim 4. 4a; Kıl şaftı ve bulbus . 4b; Ekrin ter bezleri ortaları; parlak, oval-yuvarlak, spiral yapılar (kırmızı ok)

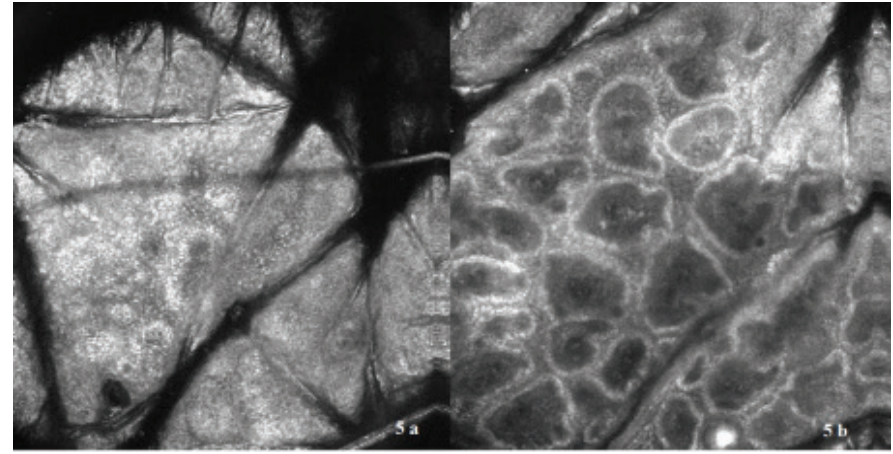

Resim 5. Konjenital melanositik nevüs. 5a; Epidermal tabakada parlak kaldırım taşı şeklinde pigmente keratinositler. 5b; Refraktil hücrelerle çevrilmiş düzenli papillalar.

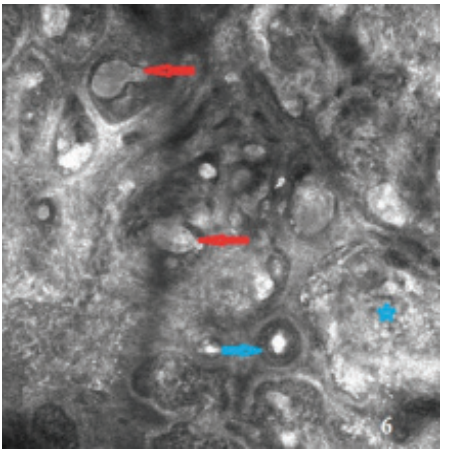

Resim 6. Bileşke nevüsü (Junctional). Dermal papillalarla bağlantılı papilla içlerine uzantı gösteren bileşke kümeleri (kırmızı oklar). Ortası oldukça refraktil düzgün sınırlı milia benzeri kist (mavi ok) Papillayı tamamen doldurmuş dermal hücre kümeleri (mavi yıldız)

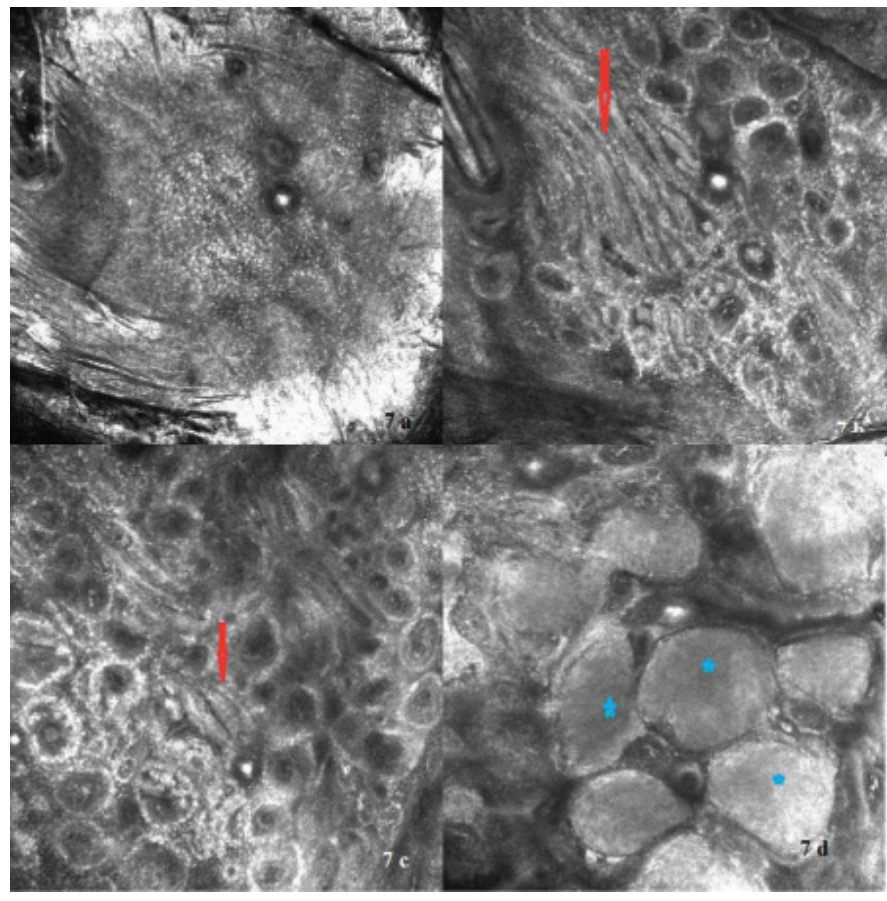

Resim 7. Bileşik nevüs (Compound). 7a; Epidermiste kaldırım taşı paterni. 7b-7c; Bileşke kalınlaşmaları (kırmızı ok) 7d; Dermiste yerleşmiş keskin sınırlı papillaları tamamen dolduran dermal nestler (mavi yıldız) 


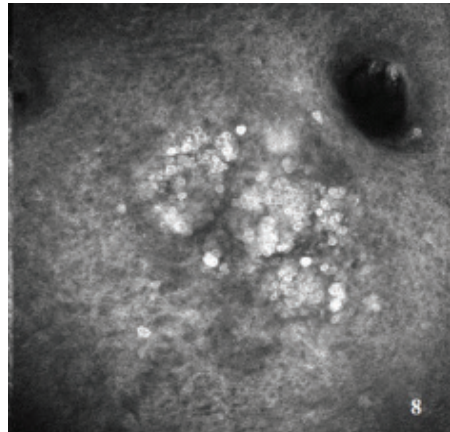

Resim 8. Dermal nevus. Dermiste nevus hücre kümeleri

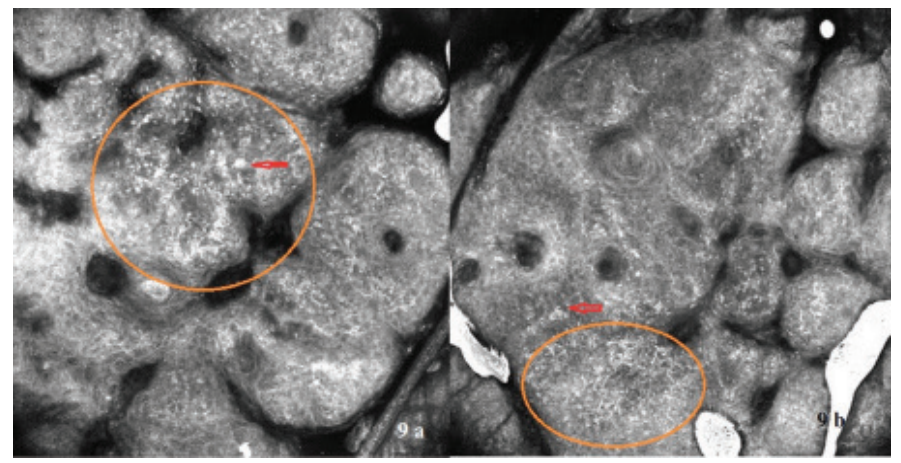

Resim 9. Displastik nevus. 9a-9b; Papillaların net şeçilemediği, az sayıda, yuvarlak parlak atipik melanositik hücreler (kırmızı ok). Çok sayıda dentritik hücre (turuncu halka)

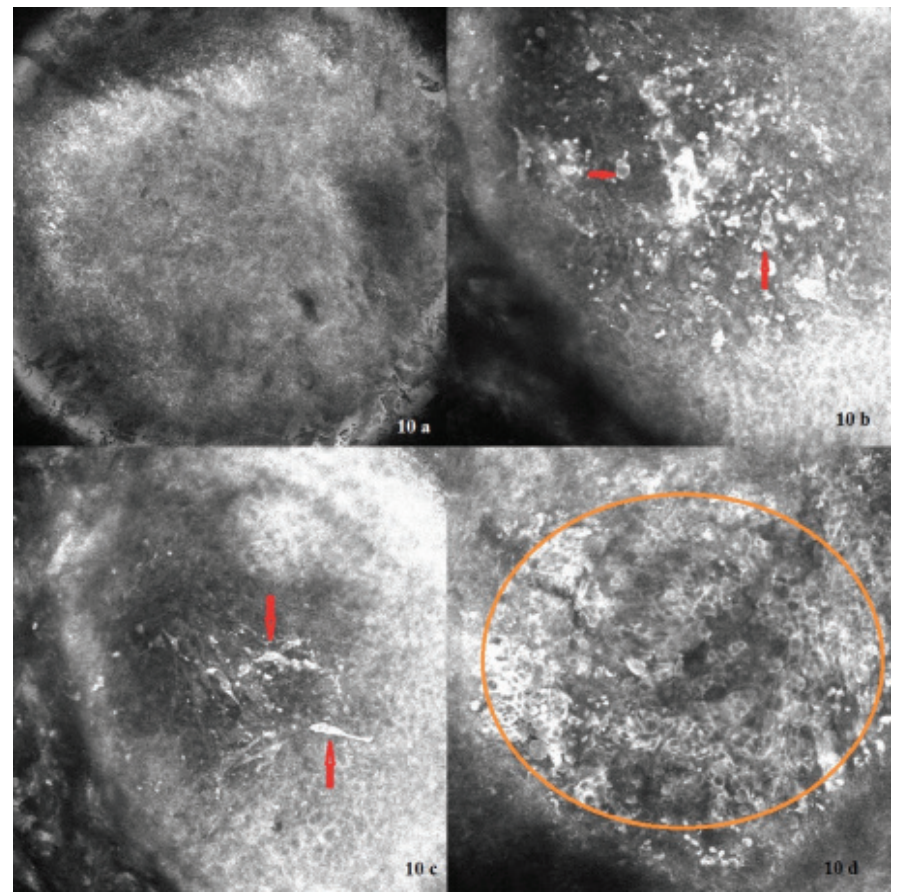

Resim 10. Melanom. 10 a; Epidermiste bozulmuş yapı. 10b; Dermiste dağınık yerleşimli yuvarlak pajetoid hücreler(kırmızı ok). 10 c; Dermiste küme oluşturmuş dentritik hücreler (kırmızı ok).10 d; Atipik hücrelerin oluşturduğu tümör yapısı

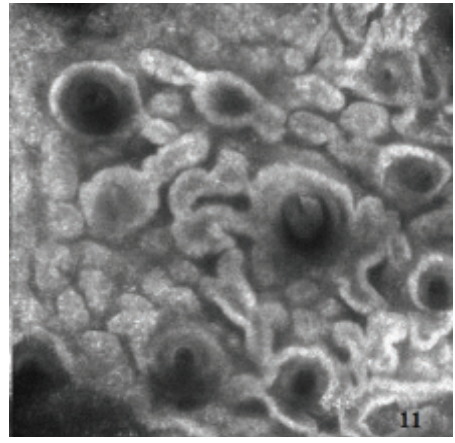

Resim 11. Lentigo. Polisiklik papiller sınırlar

Bazen hücre kümeleri adneksal veya vasküler yapılar boyunca görüntülenebilir. Bu özellik konjenital paterni akla getirmelidir. KMN'de saptanan diğer özellikler hafif gevşek hücre kümeleri, dermisteki melanosit kordonları ve papiller dermisteki nükleuslu refraktil hücrelerdir (Resim 5)22.

Edinsel melanositik nevus: Bu tip nevuslarda bazal tabakada, merkeze yerleşmiş nükleusu bulunan, monomorf, yuvarlak-oval, parlak refraktil hücreler bulunur. Nadiren nevus hücreleri kısa ve ince dendritler taşıyabilir. Epidermisteki bal peteği görüntüsü korunmuştur. Nevus hücreleri genellikle keratinositlerden daha büyük ve sitoplazmaları oldukça refraktildir. Dermal papillalar düzgün dağıımlıdır ve küçük melanositler ve melaninden zengin keratinositlerin oluşturduğu refraktil hücrelerle çevrelenmiştir23

a) Bileşke nevusları (junctional nevus): Nevus hücreleri sadece dermoepidermal (DEJ) bileşkede sınırlıdır (Resim 6).

b) Bileşik nevusler: Nevus hücreleri DEJ ve üst dermiste görülebilir (Resim 7).

c) Dermal nevus: Nevus hücreleri kümeler oluşturmuş şekilde dermiste tespit edilir (Resim 8) ${ }^{11}$.

Displastik nevus: Hücre popülasyonu boyut, şekil ve refraktilite açısından daha heterojendir. Hücreler banal nevuslerde olduğu gibi yuvarlak veya ovaldir. Epidermiste keratinosit hücre sınırlarında fokal silinme vardır. Atipi melanositlerdeki azalmış parlaklıkla bağlantıııdır(Resim 9)23. Sitolojik atipi ve atipik jonksiyonel kümelenmeler saptanır ${ }^{18}$. Melanom: Kalın dallanan dentritik uzantıları bulunan polimorfik, düzensiz şekilli hücrelerden oluşur. Atipik hücreler epidermisin birkaç tabakasına yayılmış olabilir bu durum pajetoid yayılımla uyumludur. Keratinosit hücre sınırları zorlukla seçilir veya yoktur. Bu da bal peteği paterninin bozulması ile sonuçlanır. Dermal papillalar küçük ve düzensizdir23 (Resim 10). Bazal tabakada atipik hücreler, parlak sınırla çevrili olmayan papilla (nonedeged), serebriform kümelenmeler izlenebilir 17. Spitz nevus: RKM ile tespit edilen uniform agrege globüller dermoskopik olarak tespit edilen globuler tip ile uyumluluk gösterir. Üst epidermiste pigment kümeleri ile uyumluluk gösteren parlak granüler parçacıklar görülebilir. Suprabazal tabakada sporadik yuvarlak-oval granüler sitoplazmalı, koyu nükleuslu, pajetoid yayılan nevomelanositler tespit edilebilir. Dermal papillalar içerisinde parlak tombul hücreler (melanofajlar)izlenebilir ${ }^{15}$.

Lentigo: RKM ile lentigo simpleks stratum granülozum ve spinozumda karakteristik balpeteği paterni, hiperrefraktil bazal tabaka kaldıım taşı paterni gösterir. Dermal papiller halkalar parlak monomorfik hücrelerden oluşan tek bir tabaka oluşturur(Resim 11) ${ }^{16}$. 


\section{Kaynaklar}

1. Rajadhyaksha M, Grossman M, Esterowitz D, Webb RH, Anderson RR: In vivo confocal scanning laser microscopy of human skin: melanin provides strong contrast. J Invest Dermatol 1995:104:946-52.

2. Busam KJ, Charles C, Lee G, Halpern AC: Morphologic features of melanocytes, pigmented keratinocytes, and melanophages by in vivo confocal scanning laser microscopy. Mod Pathol 2001;14:862-68.

3. Langley RG, Rajadhyaksha M, Dwyer PJ, et al: Confocal scanning laser microscopy of benign and malignant melanocytic skin lesions in vivo. J Am Acad Dermatol 2001;45:365-76.

4. Pellacani G, Cesinaro AM, Seidenari S: Reflectance-mode confocal microscopy of pigmented skin lesions-improvement in melanoma diagnostic specificity. J Am Acad Dermatol 2005:53:979-85.

5. Guitera P, Pellacani G, Crotty KA, et al: The impact of in vivo reflectance confocal microscopy on the diagnostic accuracy of lentigo maligna and equivocal pigmented and nonpigmented macules of the face. J Invest Dermatol 2010;130:2080-91.

6. Gerger A, Wiltgen M, Langsenlehner $U$, et al: Diagnostic image analysis of malignant melanoma in in vivo confocal laser-scanning microscopy: a preliminary study. Skin Res Technol 2008;14:359-63.

7. Segura S, Puig S, Carrera C, Palou J, Malvehy J: Development of a two-step method for the diagnosis of melanoma by reflectance confocal microscopy. J Am Acad Dermatol 2009;61:216-29.

8. Gonzalez S, Swindells K, Rajadhyaksha M, Torres A: Changing paradigms in dermatology: confocal microscopy in clinical and surgical dermatology. Clin Dermatol 2003;21:359-69.

9. Rajadhyaksha M, Gonzalez S, Zavislan JM, Anderson RR, Webb RH: In vivo confocal scanning laser microscopy of human skin II: advances in instrumentation and comparison with histology. J Invest Dermatol 1999;113:293-303.

10. Hofmann-Wellenhof R, Wurm EM, Ahlgrimm-Siess $V$, et al: Reflectance confocal microscopy-state-of-art and research overview. Semin Cutan Med Surg 2009;28:172-79.

11. Branzan $A L$, Landthaler $M$, Szeimies RM: In vivo confocal scanning laser microscopy in dermatology. Lasers Med Sci 2007;22:73-82.

12. Scope A, Benvenuto-Andrade C, Agero AL et al: In vivo reflectance confocal microscopy imaging of melanocytic skin lesions: consensus terminology glossary and illustrative images. J Am Acad Dermatol 2007;57:644-58.
13. Ahlgrimm-Siess $V$, Massone $C$, Koller $S$, et al: In vivo confocal scanning laser microscopy of common naevi with globular, homogeneous and reticular pattern in dermoscopy. Br J Dermatol 2008;158:1000-7.

14. Pellacani G, Cesinaro AM, Seidenari S: In vivo confocal reflectance microscopy for the characterization of melanocytic nests and correlation with dermoscopy and histology. Br J Dermatol 2005;152:384-6.

15. Pellacani G, Cesinaro AM, Grana C, Seidenari S: In vivo confocal scanning laser microscopy of pigmented Spitz nevi: comparison of in vivo confocal images with dermoscopy and routine histopathology. J Am Acad Dermatol 2004;51:371-6

16. Langley RG, Burton E, Walsh N, Propperova I, Murray SJ: In vivo confocal scanning laser microscopy of benign lentigines: comparison to conventional histology and in vivo characteristics of lentigo maligna. J Am Acad Dermatol 2006;55:88-97.

17. Pellacani G, Vinceti M, Bassoli S, et al: Reflectance confocal microscopy and features of melanocytic lesions: an internet-based study of the reproducibility of terminology. Arch Dermatol. 2009;145:1137-43.

18. Pellacani G, Farnetani F, Gonzalez S, et al: In vivo confocal microscopy for detection and grading of dysplastic nevi: a pilot study. J Am Acad Dermatol 2012;66:109-21.

19. Debarbieux S, Depaepe L, Poulalhon N, Balme B, Dalle S, Thomas L: Reflectance confocal microscopy accurately discriminates between benign and malignant melanocytic lesions exhibiting a 'dermoscopic island': J Eur Acad Dermatol Venereol 2013;27:159-65.

20. Pupelli G, Longo C, Veneziano L, et al: Small-diameter melanocytic lesions: morphological analysis by means of in vivo confocal microscopy. $\mathrm{Br} J$ Dermatol 2013;168:1027-33.

21. Guitera P, Pellacani $G$, Longo $C$, et al: In vivo reflectance confocal microscopy enhances secondary evaluation of melanocytic lesions. J Invest Dermatol 2009;129:131-8.

22. Marghoob AA, Charles CA, Busam KJ, et al: In vivo confocal scanning laser microscopy of a series of congenital melanocytic nevi suggestive of having developed malignant melanoma. Arch Dermatol 2005;141:1401-12.

23. Gerger A, Hofmann-Wellenhof R, Samonigg H, Smolle J: In vivo confocal laser scanning microscopy in the diagnosis of melanocytic skin tumours. $\mathrm{Br} J$ Dermatol 2009;160:475-81. 